\title{
ANTIMICROBIANOS PRODUCIDOS POR PLANTAS
}

\author{
Waldo Lazo \\ Laboratorio de Botánica Criptogámica \\ Departamento de Ciencias Ecológicas \\ Facultad de Ciencias, Universidad de Chile. \\ Las Palmeras 3425, Santiago (Macul), Chile
}

Palabras clave: antimicrobianos, plantas.

Key Words: antimicrobial, plant.

\section{RESUMEN}

Los principales antimicrobianos producidos por plantas son: ácido sórbico producido por Sorbus aucuparia $L$.; berberina por Berberis vulgaris $L$.; aliicina por Allium sativum $L_{\text {.; }}$ isotiocianato de bencilo por Tropaeolum majus $L$.; timol por Thymus vulgaris $L$. Se menciona también muchos otros antimicrobianos de menor importancia producidos por plantas.

Desde la antigüedad se sabe que ciertas plantas producen sustancias capaces de paliar o curar procesos infecciosos en el hombre, o de retardar o prevenir la descomposición de algunos alimentos al inhibir el desarrollo de organismos contaminantes en ellos.

Diversas plantas fanerógamas han sido utilizadas, a través de los siglos, debido a sus propiedades antimicrobianas. De algunas se ha conseguido aislar los principios activos como el ácido sórbico, el timol, el isotiocianato de bencilo, la berberina y la aliicina. Pero de la mayor parte de las plantas con acción antimicrobiana, en medicina natural, se usan infusiones o emplastos cuyos componentes activos son poco conocidos o desconocidos.

En los frutos de Sorbus aucuparia L. existe, en forma natural, el ácido sórbico que es un polvo blanco o blanco crema, de escaso olor, ligeramente ácido y de sabor algo astringente. Es soluble en agua fría al 1 x 1000 , en agua hirviendo al $1 \times 30$ y en etanol al $1 \times 10$. Actúa inhibiendo sistemas enzimáticos (dehidrogenasas y fumárico-oxidasas). Antagoniza el desarrollo de mohos, levaduras y en menor grado a las bacterias. $\mathrm{A}$ pH superiores a 6.5 no ejerce casi actividad antimicrobiana. No se debe añadir a la masa para hacer pan, porque inhibe la fermentación producida por la

\section{SUMMARY}

\section{[Antimicrobial agents produced by plants]}

The main antimicrobial agents produced by plants are; sorbic acid by Sorbus aucuparia $L$.; berberin by Berberis vulgaris $L$.; allicin by Allium sativum $L$.; benzyl isothiocyanate by Tropaeolum majus $L$.; thymol by Thymus vulgaris.

Other antimicrobial agents of lesser inportance produced by plants are also mentionned.

levadura, pero, el palmitato de sorbilo, que es inactivo durante la fermentación de la masa, en el proceso posterior de panificación se hidroliza y da ácido palmítico y ácido sórbico que, en este estado, ejerce su actividad antimicótica. Es uno de los preservativos más inocuos y se emplea generalmente al 1 o 2 x 1000 en preparaciones farmacéuticas o en concentraciones de hasta el 2 x 1000 en los productos alimenticios.

Con este mismo fin se lo utiliza en embutidos, en la preservación de bebidas carbonatadas, jarabes, jugos de frutas, vino y cerveza, queso, margarina, mayonesa, páis, pasteles, salchichas, escabeches de pescado, ensaladas, aderezos de ensaladas, frutas y verduras secas of frescas, picles, jaleas, gelatinas.

Para evitar el enmohecimiento externo de los quesos, se los puede sumergir en soluciones de $2.5 \%$ de sorbato de potasio.

Elácido sórbico se vende bajo el nombre propietario de Sorbistat.

Thymus vulgaris L., el fragante tomillo y Thymus serpyllum L., el "serpol", producen un conocido antiséptico: el timol, que ejerce acción fungicida y 
bactericida. Es soluble en etanol, poco soluble en agua. Es incompatible con el yodo, los álcalis y los agentes oxidantes. Su acción antimicrobiana se reduce en presencia de proteínas. Es irritante para los tejidos. Se usa para enjuagatorios bucales, en odontología y en forma de polvo para algunas dermatomicosis. Años atrás se empleo el timol en dosis de hasta 2 gramos diarios por vía bucal, para el tratamiento de blastomicosis y candidosis pulmonar. Este tratamiento cayó en desuso debido a su elevada toxicidad y poca efectividad.

De la "espuela de galán", Tropaeolum majus L., se extrae un antimicrobiano: el isotiocianato de bencilo, que se presenta bajo la forma farmacéutica de aceite y se vende con el nombre de TROMACAPS en Alemania y Suiza.

El "agracejo", Berberis vulgaris L. produce un alcaloide cuaternario: la berberina con una acción antimicrobiana que afecta a diversos gérmenes grampositivos, gramnegativos (entre los que se incluye Vibrio cholera, Escherichia coli, Shigella spp. Pseudomonas spp. etc.) hongos y algunos protozoos como Entamoeba histolytica, Giardia lamblia, Leishmania spp. Se la ha usado en el tratamiento de diversas patologías infecciosas como el cólera, la leismaniasis cutánea y otras.

Tal vez, la planta cuya acción antimicrobiana se conoce desde hace más tiempo es el "ajo", Allium sativum L. (Lazo, 1983). Su acción antibacteriana y antimicótica se debe especialmente, a la aliicina disulfuro de alilo- compuesto sulfurado de un aroma muy penetrante. La aliicina no es termoestable y pierde en poco tiempo su actividad biológica. Administrada por vía bucal en forma de ajo crudo o de extractos, da concentraciones séricas de duración breve. No se ha conseguido comprobar su presencia en la orina. El ajo se utilizó durante la edad media para el tratamiento y prevención de la peste bubónica y, según las referencias, parecería que actuó con notable eficacia en este sentido. También hay comunicaciones de médicos, incluso a principios de este siglo, que acreditan la acción de A. sativum en la tuberculosis pulmonar y otras patologías pulmonares (Bolton y col., 1982). No parece ser eficaz contra las neumonitis por Mycoplasma spp. También hay informes sobre su acción beneficiosa en la lepra, en la hidrofobia y en el SIDA. La dosis terapeutica empleada es de 12 a 14 bulbillos (dientes) crudos de ajo al día, molidos o masticados. En el bulbillo intacto no hay aliieina, hay sólo aliina. La aliicina se produce debido a la transformación que experimenta la aliina, presente en el bulbillo, por la enzima aliinasa que se libera al destruir los tejidos celulares del bulbillo.
Especies del género Nothoscordum (Lazo y Ravena, 1989) poseen en sus bulbos una sustancia de acción antimicótica y antibacteriana, pero, carecen del aroma aliáceo. No se conoce aún las características químicas de esa sustancia ni su posible utilidad.

Allium cepa L., Allium ursinum L., Alliaria oficinalis Andrz. exhiben acciones antimicrobianas que se asemejen a la acción del ajo.

Las ramitas de "natri", Solanum tomatillo Remy, contienen un factor antimicótico que es soluble en agua fría o tibia y que se destruye en agua en ebullición (Lazo, 1987). Cáceres y Jirón (1988) usaron extractos etanólicos de Solanum nigrescens para tratar candidiasis vaginal y demostraron que eran tan efectivos como el tratamiento clásico con nistatina. Los investigadores comunicaron que el principio activo es un glucoalcaloide, y que Solanum americanum posee también una marcada acción antifúngica.

La "velosilla", Hieracium pilosella L., da una umbeliferona de acción antimicótica: la 7 hidroxi cumarina que es efectiva contra la brucelosis y que está presente sólo en la planta fresca.

Las hojas de Eucalyptus globulus Labill, y las de Artemisa vulgaris L. contienen el antiséptico eucaliptol, las de Pelargonium roseum Wild. geraniol y citronelol de cierta acción antiséptica, las puntas florales de Lavándula vera DC. poseen dos antisépticos débiles: linalol y geraniol y las hojas de Melissa officinalis; linalol, citronelol y geraniol. Las hojas y frutos del "olivo", Ola europea L., un oleopeurósido de moderada acción antimicrobiana. El rizoma del "nenúfar", Nuphar luteum Sibth et Smith, el acaloide lutenurina de acción antimicrobiana. Las agujas de Pinus sylvestris $\mathrm{L}$. compuestos fenólicos antisépticos. Las hojas de Juglans regia L., juglona que ha sido usada para tratar infecciones cutáneas. La planta entera de Heliotropium europaeum L. alcaloides pirrocilidinicos de acción antiséptica. Las flores y hojas de Hyssopus officinalis L. el antiséptico tuyona. Las hojas de Pyrola umbellata $L$. un arbutósido que actúa como antiséptico de las vías urinarias. Las hojas y flores de Artemisia absinthium L., tuyona y tuyol.

El rizoma de Aristolochia clematitis L. contiene ácido aristolóquico que inhibe el desarrollo de Pseudomonas aeruginosa. La raíz de Cichorium intibus L. ácido clorogénico que es activo contra Brucella spp y Salmonella spp. Las flores y hojas de Genista tinctoria L., flavonoides que inhiben el desarrollo de Staphylococcus aureus. Las partes floridas de Grindelia robusta Nutt., polifenoles, flavonóides, y ácido grindélico que antagonizan el desarrollo de Streptococcus pneumoniae y de Haemophilus per- 
tussis. Las hojas y corteza de Hammamelis virginiana L. flavonósidos antibacterianos. El bulbo de Narcissus jonquilla $\mathrm{L}$. los antibacterianos narciclasina y pseudolicorina. Las hojas y ramitas de Hedera helix L. saponósidos de hederagina que inhiben el desarrollo de gérmenes gramnegativos, la misma acción se aprecia en la sinapina y el ácido sinápico presentes en las semillas de Sinapsis arvensis L.

En las hojas y frutos de Vaccinum myrtillus $L$. hay taninos con acción antagonista sobre el desarrollo de enterobacteriáceas. En la raíz de Cochlearia armoracia $\mathrm{L}$. un sinigrósido que por hidrólisis da isocianato de alilo con actividad contra gérmenes gramnegativos.

El fruto de Lycopersicon escullentum Mill. contiene el alcaloide antibacteriano tomatina. La raíz de Inula helenium L., lactonas sesquiterpénicas de acción inhibitoria sobre hongos dermatofitos. La raíz y hojas frescas de Arctium majus Bernh. artiopicrina activa contra dermatofitos y otros mohos. La raíz y flores de Primula oficinalis Jacq. saponósidos inhibidores de Candida spp. El rizoma y raíces de Veratrum album $\mathrm{L}$. alcaloides de acción antifúngica. Las hojas y flores de Mentha piperita L. polifenoles antimicóticos. El rizoma de Nuphar luteum Sibth et Smith el antifúngico dihidroxitiobinufaridina.
En el rizoma de Sanguinaria canadensis L. hay alcaloides con acción inhibitoria sobre el desarrollo de algunos dermatofitos. En las semillas de Glycine soja Siebold et Zucc. isoflavonas antifúngicas. En las raíces y hojas de Withania somnifera Dunal la lactona antifúngica witaferina y en la raíz de Inula helenium L. el antiviral helenina.

Los jugos frescos de Chelidonium majus L. proporcionan quelidonina y coptisina, las partes en flor de Anagalis arvensis L. saponosidos, las flores de Calendula officinalis $L$. alcoholes y lactonas terpénicas, de acción antiviral.

La decocción de corteza de frutos de Punica granatum L. inhibe el desarrollo de Staphylococcus aureus, Bacillus spp., Clostridium spp., debido, tal vez, a su alto contenido en tanino (Lazo, 1990). Su administración por vía bucal ha sido beneficiosa en pacientes con enteritis ocasionada por Clostridium difficile y en enteritis de pacientes con SIDA.

Bhakuni y col. (1976) publicaron estudios sobre la acción antibacteriana de 276 plantas chilenas. Casi un tercio de ellas presentó acción antiestafilocóccica. Solamente dieciseis inhibieron también el desarrollo de E. coli.

Hay muchos otros antimicrobianos producidos por plantas pero, hasta ahora el único de amplia utilización en la industria alimenticia y farmacéutica es el ácido sórbico.

\section{REFERENCIAS}

BOLTON, S., G., NULL Y W.M. TROETEL. (1982). The medical uses of garlic, fact and fiction. Am.Pharmacy NS22 (8): 40-43.

BHAKUNI, D. S.; M. BITTNER; C. MARTICORENA; M. SILVA; E. WELDT and MELO, M.E; ZEMELMAN, R. (1974). Screening of Chilean plants for antimicrobial activity. Lloydia 37 (4): 621-632.

CACERES, A.; L.M. GIRON. (1988). Investigación aplicada integral sobre las plantas medicinales en Guatemala. Centro Mesoamericano de Estudios sobre Tecnología Aplicada CEMAT. Guatemala.

CHEIJ, R. (1983). Guía de las plantas medicinales. Barcelona.
LAZO, W. (1983). Acción antifúngica de Allium sativum. Bol. Micol. 1: 185-186.

LAZO, W. (1987). Acción antimicótica de algunas plantas Chile nas. Bol. Micol. 3: 191-193.

LAZO, W.; P. RAVENNA (1989). Acción antimicrobiana de tres especies del género Nothoscordum (Altiaceae). Bol. Micol. 4: 91-92.

LAZO, W. (1990). Acción Antomicrobiana de algunas plantas de uso medicinal en Chile. 1 Bol. Micol. 5 : $25-28$

VIGNEAU, C. (1985). Plantes Medicinales. Ed. Masson. Paris. 